\title{
Trust in an unwanted service environment: The case of pregnancy termination counselling services
}

\author{
Authors: \\ Rachelle Ebersohn ${ }^{1}$ \\ Edwin Theron ${ }^{1}$ \\ Affiliations: \\ ${ }^{1}$ Department of Business \\ Management, Stellenbosch \\ University, South Africa \\ Correspondence to: \\ Edwin Theron \\ Email: \\ et3@sun.ac.za \\ Postal address: \\ Private Bag X1, Matieland \\ 7602 , South Africa \\ Dates: \\ Received: 14 Oct. 2013 \\ Accepted: 04 June 2014 \\ Published: 20 Aug. 2014 \\ How to cite this article: \\ Ebersohn, R. \& Theron, E., \\ 2014, 'Trust in an unwanted \\ service environment: \\ The case of pregnancy \\ termination counselling \\ services', Acta Commercii \\ 14(1), Art. \#233, 8 pages. \\ http://dx.doi.org/10.4102/
} ac.v14i1.233

\section{Copyright:}

(C) 2014. The Authors. Licensee: AOSIS OpenJournals. This work is licensed under the Creative Commons Attribution License.
Orientation: The South African Termination of Pregnancy Act (No 92 of 1996) promotes the use of non-mandatory counselling before and after a pregnancy is terminated. The reality is, however, that not all women who are faced with the issue of termination are necessarily willing to undergo counselling. The literature revealed that this unwillingness could partly be ascribed to the fact that women do not necessarily trust counsellors and the research thus addressed the question how trust can be managed within this industry.

Research purpose: The purpose of the research reported here was to investigate the influence of communication, empathy, shared values, competence, reputation and support services on trust within the pregnancy termination counselling industry.

Research design, approach and method: A quantitative approach was used to assess the significance of the hypothesised relationships. Self-administered questionnaires were used to target 175 female students of a leading South African university. The data were analysed using regression analysis.

Main findings: The results of the study contradict some often-assumed antecedents of trust.

Managerial implications: Trust within the pregnancy termination counselling industry can be managed by services providers through focusing on personalised communication, empathy, reputation, support services and rapport.

Contribution/value-add: The value of the article is twofold: Firstly, based on the findings, at practitioner level, abortion counsellors will be assisted in how to deal with clients to create trust. Secondly, the findings from the study will assist academics to understand the nature of the unwanted services industry better. Services providers and other policy makers have to rethink their current approaches through which trust is built within the abortion counselling industry.

\section{Introduction}

Certain products and services can be classified as unsought or unwanted as a result of customers choosing not to think about them regularly (Kotler \& Keller 2009). Although no clear definition or classification of the unwanted services industry exists, some services are generally assumed to be of an unwanted nature - such as funeral services, pest control and plumbing services. The pregnancy termination counselling industry could be regarded as a further example of such an industry.

Although different dimensions exist through which relationships can be established and managed in the long run, trust appears to be one of the basic building blocks of any relationship, whether it be a personal or a business relationship (Dagger \& O'Brien 2010; Liang \& Wang 2008). The pregnancy termination counselling industry is not an exception to the rule; in fact, it can be argued that trust could be even more important when the industry is associated with such a high level of emotional involvement (Stayt 2009). Once the decision has been taken to make use of pregnancy termination counselling, the focus shifts to the counsellor to develop the assurance of trustworthiness. However, literature regarding the way in which trust can be managed in the unwanted services industry is limited; even less is available in the case of pregnancy termination counselling services.

\section{The unwanted services industry}

'Unwanted services' refers to services that could evoke strong negative emotions, resulting in an unreceptive buying situation (Xu, Summers \& Belleau 2004). Authors appear to have different ways to describe the unwanted services industry, such as 'unmentionables' (Wilson \& West 1981), 'controversial products/services' (Fam, Waller \& Erdogan 2004) and 'offensive services' (Waller 
1999). Fam et al. (2004) describe controversial products and services as being those products and services that, for reasons of delicacy, decency, morality or even fear, tend to elicit reactions of distaste, disgust, offence or outrage when mentioned or when presented openly. For the purposes of this study, unwanted services were defined as services that are not needed or not wanted, services that are undesirable and something consumers would not normally consider buying or acquiring. Badger (2008) claims that marketers of unwanted services have the difficult and challenging task of attracting customers who do not want to be attracted by them, or who do not want the service.

The availability of literature about unwanted services is limited. One of the few studies within the field of unwanted services was that by Schwartz, Jolson and Lee (1986) who used the funeral service industry as the focal point of their study. According to Schwartz et al. (1986), three uncommon conditions are normally present in the case of an unwanted service. Firstly, the purchaser of the service has not, prior to the situation, sought out or searched for any information about the possible options or the cost considerations; thus, the industry is confronted by a negative demand for the service in question. Secondly, the purchase cannot be avoided and there are substantial time pressures present. The consumer is often in a situation of immediate need, thus he or she does not have the time available to look around for the best possible option or deal. Lastly, the emotional state of the buyer has a strong influence on the rational decision-making process.

\section{The pregnancy termination industry}

The pregnancy termination industry can be classified into two main sections: legal (or safe) services providers and illegal (or unsafe) pregnancy termination services providers. The process of terminating a pregnancy legally is known to take place in a medically-approved institution and is conducted by trained medical practitioners or nurses in a safe and responsible manner. On the other hand, unsafe (or illegal) terminations are completed in unhygienic environments that are not medically-approved. These unsafe terminations are performed by individuals lacking the required skills and medical background to perform the procedure in a safe and medically-approved manner (World Health Organization 2008). Research has shown that, in a global sense, approximately $50 \%$ of all pregnancy terminations are illegal (Guttmacher Institute 2012). Moreover, 98\% of these illegal terminations of pregnancy are conducted in developing countries, of which South Africa is one.

Although statistics on pregnancy termination are often unreliable, it is estimated that during the period 1973-2011, about 54.5 million pregnancy terminations were performed in the United States, which represents one pregnancy termination every 26 seconds (American Life League 2012). Globally, it is estimated that approximately 42 million pregnancy terminations occur every year (Edelson 2007). South African pregnancy termination statistics reveal that a total of 77771 legal terminations of pregnancy were performed in 2011, which indicates a 31\% increase since 2010 (Sowetan Live 21 August 2012). This study further found that the province with the highest pregnancy termination rate was the Free State, where 21994 pregnancy terminations were performed during 2011, followed by 12138 in the North West and 11239 in Gauteng in the same period.

\section{Pregnancy termination counselling}

Following the legalisation of pregnancy terminations in South Africa, the Choice on Termination of Pregnancy Act (No 92 of 1996) (the Act) promotes that non-mandatory counselling sessions take place before and after a pregnancy termination is undertaken (South Africa 1996). Pregnancy termination counselling can be defined as an interaction that could minimise the anxiety and confusion perceived to be associated with making a decision about whether to end or continue a pregnancy (Lee 2003). Counselling sessions are constructed in order to provide women with relevant and accurate information pertaining to the pregnancy termination process. However, few pregnancy termination centres realise the extent of the physical and psychological risks that a pregnancy termination may hold and therefore do not provide counselling as prescribed by the Act. Consequently, women are forced to make uninformed decisions regarding their unplanned pregnancy, often leading to infertility, drug abuse and even death (Elliot Institute 2009).

Counselling sessions are required to inform potential clients of the possible risks involved and of possible effects and to give information regarding alternative options (Tsilo 2007). Accordingly, as women remain uninformed about the possible risks that are involved in the pregnancy termination process and the effects of the procedure, women's general health is also declining at a noteworthy rate. The fact that the Act explicitly states that counselling should be promoted, emphasises the importance of effective pregnancy termination counselling services being available to all women who are considering a pregnancy termination.

\section{The role of trust in the pregnancy termination counselling industry}

Based on the general support for the inclusion of trust as key dimension of a relationship, Mouzas, Henneberg and Naudé (2007) argue that trust is a significant, if not pivotal, aspect of a relationship. Trust can be defined as the level of confidence an individual has in a partner's reliability and integrity (Morgan \& Hunt 1994). This definition is supported by Baron, Conway and Warnaby (2010) who argue that trust is achieved when a person can expect the word of another to be reliable, implying high levels of honesty in all areas of negotiation. Moorman, Deshpande and Zaltman (1993) consider trust to be the most important factor in relationships where a strong sense of vulnerability exists, which is typical in the case of the termination of a pregnancy. Vulnerability is often associated with perceived risk and trust can be seen as a crucial element to facilitate the reduction of risk (Ganesan \& Hess 1997). 
Trust has been found to create an environment for individuals to feel more confident in their decision to go through with a given procedure or action, by considerably reducing the sense of vulnerability and uncertainty (Berry 1995). Thus, fostering a sense of trust between the provider of pregnancy termination counselling and a potential customer will lead to more positive outcomes for both parties. If trust has been established between the client and the pregnancy termination counsellor, the client will be more likely to regard the information that she receives as valuable and therefore to make an informed decision. Clients will also be inclined to share personal information and details with the counsellor, increasing the likelihood of a relationship being formed.

\section{The antecedents of trust}

Numerous antecedents of trust were identified in the marketing literature. However, based on the uniqueness of the pregnancy termination counselling industry, the following antecedents were identified for the current study: communication, empathy, shared values, competence, reputation and support services. The justification for the inclusion of each of these antecedents is discussed below.

\section{Communication}

Communication can be defined as the sharing of relevant and timely information between parties in order to achieve a set objective (Sin et al. 2005). According to Berry (1995), open, two-way communication between a firm and its customers should take place on a regular basis in order to suggest the firm's concern for its customers' welfare. MacMillan et al. (2005) argue that parties can improve the levels of trust by improving the quality of communication that exists. Open communication lends itself to the importance of not only communicating, but also listening, which plays a fundamental role in the success of relationships in general. According to Anderson and Narus (1990), communication is one of the most important antecedents that lead to trust, but at the same time, communication can also be seen as a consequence of enhanced trust between the respective parties. Communication improves the levels of trust in that communication allows parties to resolve disputes and realign perceptions and expectations accordingly (Morgan \& Hunt 1994).

\section{Empathy}

Empathy can be described as the orientation of an entity or individual towards regarding setting another party's interests above one's own (Swan et al. 1988). According to Baron, Harris and Hilton (2009), empathy can be considered as having the consumer's best interest at heart. Empathy therefore forms part of the key dimensions in a relationship. Baronet al. (2010) further describe empathy as a specific party's ability to perceive a situation from the other party's point of view in order to increase trust. Furthermore, Grönroos (2000) stipulates that a firm may operate in an empathetic manner if, for example, it offers consumers specialised services such as convenient operating hours to satisfy consumers' individual needs. Sin et al. (2005) argue that, in essence, empathy is based on a specific party seeking to understand the desires and goals of the other party and thus acting in a way that mutually achieves these goals together with one's own. In view of the pregnancy termination industry, it is of great importance for services providers to be able to recognise and satisfy each client's needs individually and to provide a service unique to each client's situation.

\section{Shared values}

Shared values reside in the evaluation of one's own beliefs and goals and those of other people, to determine whether a sense of congruency exists (Morgan \& Hunt 1994). In other words, people will compare their own beliefs about what they consider right or wrong, important or unimportant, as well as comparing their general behaviour cues with those of the other, to establish whether similarities exist. If the two parties do in fact share the same goals or values and are able to identify with each other, comfort levels are increased and interpersonal barriers are reduced, resulting in a stronger sense of trust (Coulter \& Coulter 2003). Johnson and Grayson (2005) argue that individuals who perceive a sense of shared goals or similarity tend to respond cooperatively towards the other party, resulting in higher levels of trust. Thus, individuals who can relate to the other in terms of values or goals will be more likely to trust them and regard their advice or suggestions as valuable.

According to Swan, Bowers and Richardson (1999), trust is more likely to exist between parties when a sense of similarity has been established. At the same time, individuals who share the same goals or values often expect to share relevant information as well as receive help when needed, as the belief exists that both parties will act in such a way as to achieve the same goal effectively (Brink \& Berndt 2008). Morgan and Hunt (1994) conclude that shared values should be considered one of the most influential antecedents in fostering high levels of trust within a relationship context.

\section{Competence}

Coulter and Coulter (2003) suggest that competence is an individual's ability to perform a certain task effectively, based on the required (expert) skills he or she has attained as a result of training or knowledge. Consequently, competence reduces a customer's sense of vulnerability and uncertainty during encounters, resulting in higher levels of trust being established between parties (Selnes 1998). Furthermore, Guenzi and Georges (2010) define expertise as an individual's knowledge and technical aptitude to provide solutions to specific problems. It is thus evident that expertise is incorporated into the aspect of competence, since an individual must have acquired the necessary skills before he or she can become an expert.

Service providers can be evaluated on the level of expertise they possess, based on the level of experience and knowledge they have obtained in the specific industry (Johnson \& Grayson 2005). Expertise is further expressed 
as an individual's ability to deliver on his or her promises (Doney \& Cannon 1997), relating to competence as being an individual's aptitude to apply his or her expertise efficiently within each situation where he or she is found (Coulter \& Coulter 2003). Doney and Cannon (1997) conclude that expertise has a direct effect on an individual's perception that a party can or cannot be trusted, which is supported by Moorman et al. (1993) who also postulate that trust can be based on an individual's level of expertise.

\section{Reputation}

Doney and Cannon (1997) define reputation in terms of a supplier as the extent to which firms and other parties within a specific industry believe that a supplier operates in an honest manner and is genuinely concerned about his or her customers' best interests. Ganesan (1994) suggests that individuals are more inclined to trust services providers who have obtained a reputation of fairness than one of high stature or success. A reputation for fairness is based on the premise of a party's tendency to display reliable and consistent behaviour over a period of time (Ganesan 1994). Ganesan then concludes that a reputation for fairness will have a positive effect on the individual's perception of the credibility of the services provider.

Considering the nature of the pregnancy termination counselling service, the importance of empathy being part of a counselling centre is clear. What is more, the reputation of a services provider assists individuals with no prior experience with a counselling centre, to form a generalised opinion and expectation before any decisions are made (Johnson \& Grayson 2005). In other words, a services provider's reputation relates to what other people and organisations say about such services provider, which in turn has a direct impact on the services provider's level of trustworthiness (Doney \& Cannon 1997). Therefore, firms need to assess all opportunities that may arise very carefully in order to determine the firm's nature and potential effects on their reputation.

\section{Support services}

A crisis situation, such as an unplanned pregnancy, may cause a woman to experience a range of negative feelings or emotions such as anxiety, stress and fear. This has a significant effect on her general emotional and psychological stability; accordingly, this gives rise to the importance of pregnancy termination counselling structures to be in place (Lee 2003). Additional services, such as support groups, are provided by counselling centres in order to provide a customised service to those clients requiring it, which automatically differentiates each counselling centre from the others. Seabury, Seabury and Garvin (2011) suggest that support services be provided to clients based on the level of each client's support network, which refers to the amount of support clients receive from friends, family and partners. Counselling centres are thus required to provide clients with customised support services according to their specific situation in order to be regarded as effective (Surman 2001).
Winslow (1998) stipulates that formal support systems, such as support groups, allow individuals to experience a sense of community, which enhances their ability to connect with and relate to others sharing a similar experience. Furthermore, it has been established that support groups play a noteworthy role in improving individuals' emotional as well as psychological state, enhancing their overall quality of life (Seabury et al. 2011). Evidently, the assumption can be made that counselling centres offering support services to suit individual clients' needs will portray increased levels of benevolence as clients may perceive the services provider to be interested in protecting their interests at all costs. Accordingly, it is proposed that counselling centres offering support services may be regarded as more trustworthy than those that do not.

Based on the literature review, the following hypotheses were formulated:

$\mathbf{H}_{1}$ : There is a positive relationship between communication and trust.

$\mathbf{H}_{2}$ : There is a positive relationship between empathy and trust.

$\mathbf{H}_{3}$ : There is a positive relationship between shared values and trust.

$\mathbf{H}_{4}$ : There is a positive relationship between competence and trust.

$\mathbf{H}_{5}$ : There is a positive relationship between reputation and trust.

$\mathbf{H}_{6}$ : There is a positive relationship between support services and trust.

\section{Problem statement and objectives}

The fact that the Act promotes the use of pre-pregnancy termination counselling indicates a need for effective counselling services to be put in place (Evangelisti 2000). In such a situation, where an individual is faced with the difficult decision regarding unplanned pregnancy, the pregnancy termination counsellor can minimise perceived risk by fostering and maintaining an appropriate level of trust (Ganesan \& Hess 1997). Consequently, a gap exists in the literature concerning how providers of pregnancy termination counselling services can manage trust. As far as could be ascertained, no previous study exists in which the antecedents of trust within the pregnancy termination counselling services industry had been established. The primary objective of the current study was, therefore, to develop a framework within which trust in the pregnancy termination counselling industry can be managed successfully.

\section{Research method and design}

The study focused on first-year students at a leading South African university, with emphasis being placed on young South African women between the ages of 18 and 19 , since these individuals are at the age characterised as being most sexually active (Panday et al. 2009). Accordingly, women in this particular age group would thus be more 
likely to undergo or face a decision pertaining to unplanned pregnancy (and thus pregnancy termination counselling) than women in other age groups.

The measurement instrument comprised of 35 questionnaire items and it was predetermined that a sample size of 200 would suffice, given the statistical techniques employed during the analysis of the data. A seven-point Likert-type scale was used, with five items being included on each of the six antecedents (as well as the dependent variable). The final questionnaire therefore consisted of 35 items. Each of the questionnaire items that was found in the measurement instrument was derived from a variety of studies that have developed well-established questionnaire items that were in accordance with reliability standards. The items were predominately sourced from Wilson et al. (2012), MacMillan et al. (2005), Coote, Forrest and Tam (2003), Doney and Cannon (1997) and Ganesan and Hess (1997).

Considering the sensitive nature of the study, ethical clearance had to be obtained from the Research Ethics Committee of the participating university. Data collection took place during scheduled lectures, and without the presence of male students. The context and nature of the study were explained to respondents, and a letter of consent was completed before the questionnaires were distributed. Once the respondents had read the cover letter and had signed the consent form, they were permitted to start answering the questionnaire.

IBM SPSS Statistics for Windows, version 20.0 (IBM Corp., Armonk, NY, 2011) was used to analyse the data. Techniques were employed to limit non-response error, whilst missing values were addressed through the mean-replacement technique.

\section{Results}

\section{Realised sample and reliability}

The questionnaire contained a screening question, requiring respondents to state whether or not they would utilise a service such as pregnancy termination counselling, if they happened to be in such a situation. The respondents who responded positively to the screening question were consequently used for the statistical tests, which accumulated to 175 of the original respondents.

The reliability of the measurement instrument was determined through coefficient alphas and, based on the viewpoint of Robinson, Shaver and Wrightsman (1991), the 0.6 margin was applied as cut-off point. The reliability scores varied between 0.600 and 0.796 . The questionnaire therefore demonstrated sufficient levels of reliability.

\section{Validity analysis}

Discriminant validity was determined by means of an exploratory factor analysis. Principal axis was selected as the extraction method and the direct oblimin method (oblique factor solution) as the method of rotation. Eigenvalues were assessed using a 0.4 loading, which resulted in the extraction of five factors. The new factors were labelled according to synergy that could be detected amongst the items of which it was composed as well as the main premise that was implied by each of the items. The factors were therefore labelled 'personal communication', 'empathy', 'reputation', 'support services' and 'rapport'. After the completion of the factor analysis, the reliability statistics were once again evaluated for all the newly-constructed antecedents. Coefficient alphas ranged between 0.645 and 0.813 , which once again provided evidence of sufficient reliability. The following new set of hypotheses thus had to be developed:

$\mathbf{H}_{7}$ : There is a positive relationship between personal communication and trust.

$\mathbf{H}_{8}$ : There is a positive relationship between empathy and trust.

$\mathbf{H}_{9}$ : There is a positive relationship between reputation and trust.

$\mathbf{H}_{10}$ : There is a positive relationship between support services and trust.

$\mathbf{H}_{11}$ : There is a positive relationship between rapport and trust.

\section{Results of the linear regression analysis}

In the regression analysis, trust was stated as the dependent variable and each of the five newly-formed factors was indicated as independent variables. The results obtained from the linear regression analysis are illustrated in Table 1.

Table 1 displays personal communication with a beta value of 0.453 and a $t$-value of 8.122 , suggesting a positive association between personal communication and trust. Personal communication also obtained a significance of 0.000 , signifying $p \leq 0.001$, which implies that a positive relationship exists between personal communication and trust. Therefore, $\mathrm{H}_{7}$ was supported.

Empathy yielded a beta and $t$-value of 0.239 and 4.429 respectively, indicating that a positive association was present between empathy and trust. A significance of 0.000 was also attained, illustrating $p \leq 0.001$ and therefore leading to support for $\mathrm{H}_{8}$. The beta value (0.134) and $t$-value (2.403) that were realised for reputation also implied that a positive association was prevalent between reputation and trust. Based on a significance of $0.017, \mathrm{H}_{9}$ was accepted.

By comparison, support services obtained a beta value of 0.162 and a $t$-value of 3.390, suggesting a positive association between support services and trust. The significance (0.001) therefore also indicated that a positive relationship existed between support services and trust, as $p \leq 0.001$, which further led to support for $\mathrm{H}_{10}$.

Finally, the beta value (0.173) and $t$-value (3.388) that were attained by rapport suggested that a positive association was evident between rapport and trust. Likewise, the significance was 0.001 , which once again proposed that a positive 
TABLE 1: Results of the regression analysis.

\begin{tabular}{|c|c|c|c|c|c|}
\hline \multirow[t]{2}{*}{ Independent variables } & \multirow[t]{2}{*}{ Beta value } & \multirow[t]{2}{*}{$t$-value } & \multirow[t]{2}{*}{ Sig. } & \multicolumn{2}{|c|}{ Collinearity statistics } \\
\hline & & & & Tolerance & VIF \\
\hline Personal communication & 0.453 & 8.122 & 0.000 & 0.678 & 1.474 \\
\hline Empathy & 0.239 & 4.429 & 0.000 & 0.724 & 1.382 \\
\hline Reputation & 0.134 & 2.403 & 0.017 & 0.679 & 1.474 \\
\hline Support services & 0.162 & 3.390 & 0.001 & 0.926 & 1.080 \\
\hline Rapport & 0.173 & 3.388 & 0.001 & 0.811 & 1.233 \\
\hline
\end{tabular}

Sig, significance level; VIF, variance inflation factor.

relationship was established between rapport and trust at a $99 \%$ confidence level ( $p \leq 0.001$ ), thus supporting $\mathrm{H}_{11}$.

The $R$-square was 0.643 , which was satisfactory, as it suggested that $64.3 \%$ of the change observed in trust could be ascribed to the independent variables. Furthermore, all the variance inflation factor (VIF) index and tolerance levels depicted in Table 1 were within the generally accepted margins. It thus appeared that multicollinearity amongst the independent variables was not a problem.

\section{Ethical considerations}

Considering the nature of the research, certain ethical procedures were undertaken before the survey could be conducted. A consent form specifying the respondent's voluntary participation, a description of the study, as well as contact details regarding relevant support (in the case of possible trauma), was also included as part of the final measurement instrument. Moreover, no demographic or personal information was required, protecting the respondents' anonymity and privacy. The research proposal, together with the finalised measurement instrument, was thus submitted to the respective representatives of the Ethical Committee, after which the ethical documentation was completed. The research study was approved on the stated ethical grounds, granting the researcher the necessary permission to continue with the study.

\section{Discussion}

\section{Managerial implications}

The concept 'personal communication' may be traced back to the definition of communication proposed by Anderson and Narus (1990), which suggests that relevant and accurate information be shared in a timely manner. The emphasis is placed on the relevance and appropriateness of the information that is shared. Therefore, once appointments have been made with a client, the counsellor should ask the client which information or issue the client wants the counsellor to focus on, in order to give the counsellor the opportunity during counselling sessions in order to gather and convey information that is relevant to the client's situation. Furthermore, service providers should include regular, compulsory training programmes that counsellors should complete, to ensure that their communication skills are at a satisfactory level. These training programmes should be designed to determine the level of communication skills that the counsellors have, and to identify areas for improvement.
Training programmes should equip counsellors with the skills to be empathetic and to provide relevant and timely information in a practical and comprehensible manner, which will allow clients to implement specified suggestions with relative ease in their daily lives.

Empathy is regarded as being a very important dimension for establishing trust and the results obtained during the current study suggested that the relationship between empathy and trust is consistent with this generally-held belief. First of all, in the light of different individuals possessing different personality types, it is critical for managers of counselling centres to ensure that counsellors are employed to suit their specific job descriptions, since not all personality types will be able to provide an empathetic service. It is suggested that the empathetic nature of the service should be applied practically in all aspects of the counselling sessions. In other words, a counsellor should be able to place his or her clients' needs above his or her own and devote him- or herself fully to the client in order to come up with a practical solution to a specific problem. In another sense, counselling advice that is provided to specific individuals must be reasonably easy to implement in the individual's daily life.

The results indicate that, in the case of pregnancy termination counselling, most respondents wanted to be counselled by an expert or a well-known counsellor (reputation of the counsellor). Communication efforts should thus emphasise the qualifications and expertise obtained by the counsellors at the specific counselling centre, as well as their level of experience. Counsellors with minimum qualifications and experience should receive a sufficient amount of training in crisis counselling and should initially accompany experts in counselling sessions in order to gain first-hand experience of what is expected of them. Training programmes should be designed in such a way that it would indicate the different levels of crisis counselling expertise or knowledge a counsellor may have acquired. In the case of an expert counsellor, it may be advisable for newly-trained counsellors to be introduced to the clients by experts. The trust and confidence that the client has in the expert, is likely to be transferred to the client's perception and expectation of the new counsellor. In order for counselling centres to protect and maintain their reputation, clients must be provided with a secure platform (customer service enquiry system) to express their negative service experiences or suggestions.

Empirical support was found for the relationship between support services and trust. It can thus be concluded that many 
individuals would rather be counselled individually and anonymously, without the inclusion of other individuals in the counselling process. In contrast, some individuals preferred the option of receiving counselling in a group or including their family members in counselling sessions. Therefore, if counselling centres have support services of any kind, it is advisable that these be emphasised in their advertising attempts, in case of any individual requiring such a service. These services should also be indicated clearly as being optional, since many individuals will refrain from utilising counselling centres if they were to perceive that group or family counselling sessions were the norm.

Considering the emotionally-charged nature of the pregnancy termination counselling industry, rapport is also of particular importance. As a result, counsellors should establish an environment where the client will feel safe. Once this environment exists, clients will be more likely to connect with counsellors. In the final instance, this connection can only be created if the client feels that the counsellor cares about the client's feelings. On a practical level, this environment can be created if counsellors adjust their communication messages to state explicitly that the counsellor views clients as ordinary people who need help and that he or she is easy to talk to.

\section{Limitations}

A number of limitations of this study manifested. Firstly, because of the sensitivity of the subject under study, it is possible that some of the respondents could have indicated inaccurate answers (thereby creating social desirability bias). Furthermore, the use of non-probability judgement and convenience sampling has resulted in a situation where the sample was not representative of the entire South African female population. Generalisation of the results to the entire unwanted services industry could therefore be questioned. For example, although the funeral services industry and the pregnancy termination counselling industry might appear to be similar in terms of nature, this cannot be assumed.

\section{Recommendations for future research}

The study presents a number of areas for future research. Although the matter was outside the scope of the present study, it might have been noteworthy to assess the influence of client demographics on the perceptions of trust in this specific industry. Consideration of, especially, the influence of culture on the establishment of trust in the pregnancy termination counselling industry might be useful for managing trust in the future.

\section{Conclusion}

In order to increase the usefulness and applicability of the results of the study, the research needs to be replicated in other unwanted services industries. Once these replications have been completed it will be possible to classify the different unwanted services industries in respect of the commonalities between them. Ultimately, this classification could provide different unwanted services industries with the opportunity to share from each other's experience regarding the way in which trust could be managed within the respective industries.

\section{Acknowledgements Competing interests}

The authors declare that they have no financial or personal relationship(s) which may have inappropriately influenced them in writing this article.

\section{Authors' contributions}

R.E. (Stellenbosch University) was the student upon whose research this article is based. E.T. (Stellenbosch University) was the supervisor for the study and assisted in the writing of the article.

\section{References}

American Life League, 2012, Abortion, viewed 21 April 2013, from http://www.all.org/ nav/index/heading/OQ/cat/ MzQ/id/NjA3OQ/

Anderson, J.C. \& Narus, J.A., 1990, 'A model of distributor firm and manufacturer firm working partnerships', Journal of Marketing 54(1), 42-58. http://dx.doi. org/10.2307/1252172

Badger, J., 2008, 'Turning "cold sellers" into "must haves": Marketing unsought library products', paper presented at the Australian Library and Information Association Biennial Conference, 02-05 September, Alice Springs, Australia.

Baron, S., Conway, T. \& Warnaby, G., 2010, Relationship marketing: A consumer experience approach, Sage Publications Ltd, London.

Baron, S., Harris, K. \& Hilton, T., 2009, Services marketing: text and cases, 3rd edn., Palgrave MacMillan, London.

Berry, L.L., 1995, 'Relationship marketing of services - growing interest, emerging perspectives', Journal of the Academy of Marketing Science 23(4), 236-245. http://dx.doi.org/10.1177/009207039502300402

Brink, A. \& Berndt, A., 2008, Relationship marketing \& customer relationship management, Juta Academic Publishers, Cape Town.

Coote, L.V., Forrest, E.J. \& Tam, T.W., 2003, 'An investigation into commitment in nonWestern industrial marketing relationships', Industrial Marketing Management 32(7), 595-604. http://dx.doi.org/10.1016/S0019-8501(03)00017-8

Coulter, K.S. \& Coulter, R.A., 2003, 'The effects of industry knowledge on the development of trust in service relationships', International Journal of Research in Marketing 20(1), 31-43. http://dx.doi.org/10.1016/S0167-8116(02)00120-9

Dagger, T.S. \& O'Brien, T.K., 2010, 'Does experience matter? Differences in relationship benefits, satisfaction, trust, commitment and loyalty for novice and experienced service users', European Journal of Marketing 44(9/10), 1528-1552. http://dx.doi. org/10.1108/03090561011062952

Doney, P.M. \& Cannon, J.P., 1997, 'An examination of the nature of trust in buyer-seller relationships', Journal of Marketing 61(2), 35-51. http://dx.doi. org $/ 10.2307 / 1251829$

Edelson, E., 2007, Abortion numbers fall worldwide, viewed 16 July 2014, from http:// consumer.healthday.com/women-s-health-information-34/abortion-news-2/ abortion-numbers-fall-worldwide-609085.html

Elliot Institute, 2009, Abortion's harm to women, viewed 29 April 2013, from http:// www.theunchoice.com/pdf/FactSheets/RecentResearch.pdf

Evangelisti, L., 2000, 'Adolescent pregnancy resolution with special reference to pre-abortion counselling', unpublished M.A. (S.W.) (Medical) dissertation, Stellenbosch University.

Fam, K-S., Waller, D.S. \& Erdogan, B.Z., 2004, 'The influence of religion on attitudes towards the advertising of controversial products', European Journal of Marketing 38(5/6), 537-555. http://dx.doi.org/10.1108/03090560410529204

Ganesan, S., 1994, 'Determinants of long-term orientation in buyer-seller relationships', Journal of Marketing 58(2), 1-19. http://dx.doi.org/10.2307/1252265

Ganesan, S. \& Hess, R., 1997, 'Dimensions and levels of trust: Implications for commitment to a relationship', Marketing Letters 8(4), 439-448. http://dx.doi. org/10.1023/A:1007955514781

'Government worried about escalating abortions', 2012, Sowetan Live, 21 August, viewed 15 April 2013, from http://www.sowetanlive.co.za/news/2012/08/21/ government-worried-about-escalating-abortions

Grönroos, C., 2000, Service management and marketing: A customer relationship management approach, 2nd edn., John Wiley \& Sons, Ltd., West Sussex.

Guenzi, P. \& Georges, L., 2010, 'Interpersonal trust in commercial relationships: Antecedents and consequences of customer trust in the salesperson', European Journal of Marketing 44(1/2), 114-138. http://dx.doi. org/10.1108/03090561011008637 
Guttmacher Institute, 2012, Facts on induced abortion worldwide, viewed 02 March 2013, from http://www.guttmacher.org/pubs/fb_IAW.html

Johnson, D. \& Grayson, K., 2005, 'Cognitive and affective trust in service relationships', Journal of Business Research 58(4), 500-507. http://dx.doi.org/10.1016/S01482963(03)00140-1

Kotler, P. \& Keller, K.L., 2009, Marketing management, 13th edn., Pearson Education Limited, New Jersey.

Lee, E., 2003, 'Tensions in the regulation of abortion in Britain', Journal of Law and Society 30(4), 532-553. http://dx.doi.org/10.1111/j.1467-6478.2003.00269.x

Liang, C-J. \& Wang, W-H., 2008, 'Do loyal and more involved customers reciprocate retailer's relationship efforts?' Journal of Services Research 8(1), 63-90.

MacMillan, K., Money, K., Money, A. \& Downing, S., 2005, 'Relationship marketing in the not-for-profit sector: An extension and application of the commitment-trus theory', Journal of Business Research 58(6), 806-818. http://dx.doi.org/10.1016/j. jbusres.2003.08.008

Moorman, C., Deshpande, R. \& Zaltman, G., 1993, 'Factors affecting trust in market research relationships', Journal of Marketing 57(1), 81-101. http://dx.doi. org/10.2307/1252059

Morgan, R.M. \& Hunt, S.D., 1994, 'The commitment-trust theory of relationship marketing', Journal of Marketing 58(3), 20-38. http://dx.doi.org/10.2307/1252308

Mouzas, S., Henneberg, S. \& Naudé, P., 2007, 'Trust and reliance in business relationships', European Journal of Marketing 41(9/10), 1016-1032. http://dx.doi. org/10.1108/03090560710773327

Panday, S., Makiwane, M., Ranchod, C. \& Letsoalo, T., 2009, Teenage pregnancy in South Africa - with a specific focus on school-going learners, viewed 17 July 2014, from http://www.gov.za/documents/detail.php?cid=244182

Robinson, J.P., Shaver, P.R. \& Wrightsman, L.S., 1991, Measures of personality and social psychological attitudes, Academic Press, San Diego.

Schwartz, M.L., Jolson, M.A. \& Lee, R.H., 1986, 'The marketing of funeral services: Past, present, and future', Business Horizons 29(2), 40-45. http://dx.doi. org/10.1016/0007-6813(86)90068-6

Seabury, B.A., Seabury, B. \& Garvin, C., 2011, Foundations of interpersonal practice in social work: Promoting competence in generalist practice, SAGE Publications, Inc., Thousand Oaks, CA.

Selnes, F., 1998, 'Antecedents and consequences of trust and satisfaction in buyerseller relationships', European Journal of Marketing 32(3/4), 305-322. http:// dx.doi.org/10.1108/03090569810204580
Sin, L.Y.M., Tse, A.C.B., Yau, O.H.M., Chow, R.P.M., Lee, J.S.Y. \& Lau, L.B.Y., 2005 'Relationship marketing orientation: Scale development and cross-cultural validation', Journal of Business Research 58(2), 185-194. http://dx.doi. org/10.1016/S0148-2963(02)00493-9

South Africa, 1996, Choice on Termination of Pregnancy Act 92 of 1996, Government Printer, Pretoria.

Stayt, L.C., 2009, 'Death, empathy and self-preservation: The emotional labour of caring for families of the critically ill in adult intensive care', Journal of Clinical Nursing 18(9), 1267-1275. http://dx.doi.org/10.1111/j.1365-2702.2008.02712.x

Surman, E., 2001, 'Challenges and dilemmas in counselling young women on pregnancy options', Reproductive Health Matters 9(17), 153-159. http://dx.doi org/10.1016/S0968-8080(01)90019-9

Swan, J.E., Bowers, M.R. \& Richardson, L.D., 1999, 'Customer trust in the salesperson: An integrative review and meta-analysis of the empirical literature', Journa of Business Research 44(2), 93-107. http://dx.doi.org/10.1016/S01482963(97)00244-0

Swan, J.E, Trawick, I.F, Rink, D.R. \& Roberts, JJ, 1988, 'Measuring dimensions of purchaser trust of industrial salespeople', The Journal of Personal Selling and Sales Management 8(1), 1-9.

Tsilo, M.M., 2007, 'Exploring the psychological sequelae of women who have undergone abortion: A multiple case-study approach', PhD thesis, Dept. of Psychology, Stellenbosch University.

Waller, D.S., 1999, 'Attitudes towards offensive advertising: An Australian study', Journal of Consumer Marketing 16(3), 288-295. http://dx.doi. org/10.1108/07363769910271513

Wilson, A. \& West, C., 1981, 'The marketing of unmentionables', Harvard Business Review 59(1), 91-102.

Wilson, A., Zeithaml, V.A., Bitner, M.J. \& Gremler, D.D., 2012, Services marketing: Integrated customer focus across the firm, McGraw-Hill, New York.

Winslow, B.W., 1998, 'Family caregiving and the use of formal community support services: A qualitative case study', Issues in Mental Health Nursing 19(1), 11-27. http://dx.doi.org/10.1080/016128498249187

World Health Organization, 2008, Unsafe abortion: Global and regional estimates of incidence of unsafe abortion and associated mortality in 2008, viewed 17 July 2014, from http://www.who.int/reproductivehealth/publications/unsafe abortion/9789241501118/en/

Xu, Y., Summers, T.A. \& Belleau, B.D., 2004, 'Who buys American alligator? Predicting purchase intention of a controversial product, Journal of Business Research 57(10), 1189-1198. http://dx.doi.org/10.1016/S0148-2963(02)00327-2 